\title{
Rancang Bangun Sistem Pengisian Baterai Nirkabel Menggunakan Mikrokontroler Teensy
}

\author{
Muhamad Amirul Haq, Muhammad Rivai, dan Tasripan \\ Departemen Teknik Elektro, Fakultas Teknologi Elektro, Institut Teknologi Sepuluh Nopember (ITS) \\ e-mail: muhammad_rivai@ee.its.ac.id
}

\begin{abstract}
Abstrak-Saat ini pemanfaatan transfer daya nirkabel sudah semakin marak. Hal ini dikarenakan transfer daya nirkabel memiliki kelebihan dimana penggunaannya lebih mudah dikarenakan tidak perlu terjadi kontak secara langsung. Pada penelitian ini, telah dibuat suatu sistem transfer daya secara nirkabel yang diperuntukkan pada stasiun pengisian baterai. Sistem transfer daya yang telah terealisasi berupa prototype fungsional yang mampu mengisi daya baterai lead-acid 6 Volt dengan kapasitas 4,5 Ah. Metode transfer daya nirkabel yang digunakan adalah metode resonant inductive coupling yang dapat bekerja secara optimal pada frekuensi $91 \mathrm{kHz}$. Pembangkitan listrik AC dengan frekuensi tersebut menggunakan H-Bridge yang dikontrol dengan microcontroller Teensy. Transfer daya nirkabel dapat berfungsi secara optimal pada jarak $20 \mathrm{~cm}$. Pada sistem pengisian daya terdapat kontrol pengisian daya constant current-constant voltage (CC-CV). Dengan adanya metode kontrol $\mathrm{CC}-\mathrm{CV}$, maka diharapkan sistem dapat mengisi daya lebih cepat dan menjaga keawetan baterai lebih lama jika dibandingkan dengan metode kontrol $\mathrm{CC}$ atau $\mathrm{CV}$ saja. Pada penelitian ini parameter transfer daya nirkabel antara lain jenis rangkaian kompensasi, jarak, dan duty cycle dari sumber $\mathrm{D}$, telah diuji hingga didapatkan efisiensi mencapai 52 persen pada jarak sejauh 20 centimeter.
\end{abstract}

Kata Kunci- Kontrol Pengisian Daya, Resonant Inductive Coupling, Transfer Daya Nirkabel.

\section{PENDAHULUAN}

$\mathrm{I}_{\mathrm{n}}^{\mathrm{D}}$ DE untuk melakukan transfer daya secara nirkabel telah muncul sejak abad ke Sembilan belas dimana Heinrich Hertz dan Nikola Tesla mengajukan teori yang menyatakan bahwa transfer daya secara nirkabel dapat diwujudkan. Penelitian mengenai transfer daya nirkabel terus dilakukan hingga pada tahun 2008 sekelompok mahasiswa MIT melakukan publikasi secara terbuka mengenai hasil pencapaian mereka dalam mentransfer daya secara nirkabel untuk menghidupkan televisi [1].

Pemanfaatan dari transfer daya nirkabel cukup beragam, mulai dari bidang kedokteran hingga industri. Pada bidang kedokteran atau medis, transfer daya nirkabel digunakan untuk mensuplai daya perangkat-perangkat elektronik implant pada tubuh seorang pasien.

Pada bidang industri, pemanfaatan transfer daya nirkabel dapat digunakan pada perangkat-perangkat yang diletakkan di tempat yang berbahaya. Dengan tidak adanya kabel maka dapat mengurangi resiko terjadinya short-circuit. Selain itu, industriindustri gadget seperti Samsung dan Apple juga sudah mulai memproduksi wireless charger untuk digunakan pada produk smartphone mereka. Selain itu, industri-industri otomotif juga mulai mengembangkan sistem transfer daya nirkabel untuk mengisi daya mobil listrik produksi mereka [2], [3].
Salah satu permasalahan pada sistem transfer daya nirkabel yang telah diterapkan adalah lamanya waktu yang dibutuhkan untuk melakukan charging pada suatu perangkat elektronik. Hal ini dikarenakan daya yang ditransfer oleh sistem cenderung konstan tanpa memperdulikan kondisi daya yang tersedia pada baterai yang diisi [4].

Saat ini pada laboratorium elektronika industri teknik elektro ITS sedang dikembangkan sebuah mobile robot yang mampu mendeteksi kebocoran gas. Robot tersebut harus mampu berpatroli mengelilingi wilayah-wilayah yang berpotensi mengalami kebocoran gas berbahaya pada industri minyak dan gas [5], [6]. Selain itu, mobile robot tersebut harus dapat beroperasi penuh secara otomatis tanpa adanya operator. Dikarenakan mobile robot tersebut akan diletakkan pada tempat yang berpotensi bahaya yang besar maka tidak dapat ditempatkan manusia untuk melakukan charging baterai pada charging station. Untuk itu, sistem transfer daya nirkabel diperlukan untuk melakukan proses charging pada baterai robot mobile robot tersebut.

Transfer daya nirkabel menggunakan prinsip mutual inductance antara dua kumparan yang mentransfer energi. Prinsip mutual inductance serupa dengan prinsip kerja transformator yang mentransfer daya dari kumparan primer menuju kumparan sekunder. Namun pada transfer daya nirkabel desain kumparan perlu diperhatikan agar antara kumparan primer (transmitter) dengan kumparan sekunder (receiver) terjadi resonansi sehingga daya yang ditransfer lebih optimal. Metode transfer daya melalui dua kumparan yang beresonansi ini disebut dengan metode resonant inductive coupling atau magnetic coupling.

Namun transfer daya nirkabel ini sendiri memiliki kelemahan dimana efisiensi daya yang ditransfer masih sangat rendah diakibatkan induktansi bocor [7]. Hal ini tentunya merupakan sebuah kerugian yang berdampak pada daya yang sampai pada receiver sistem transfer daya nirkabel jauh lebih kecil dibandingkan daya yang dikirim sehingga pengisian daya baterai akan memakan waktu yang lebih lama.

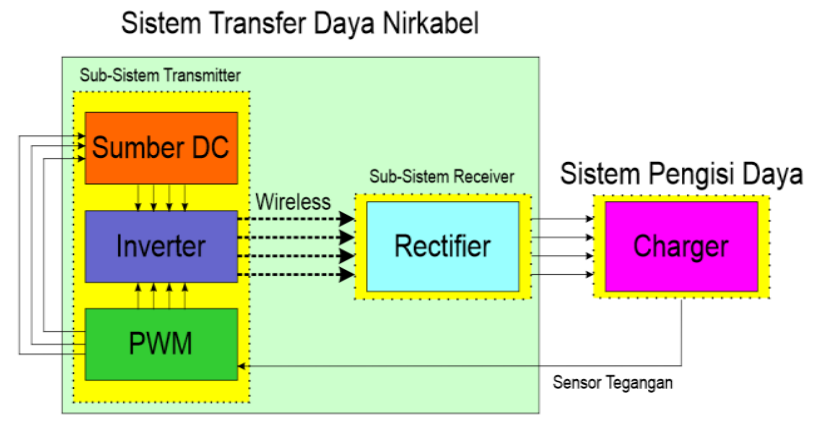

Gambar 1. Diagram sistem pengisian baterai nirkabel. 


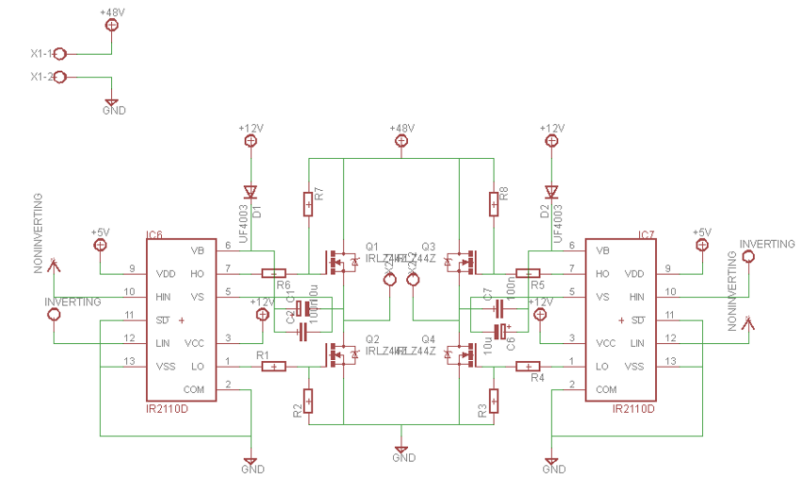

Gambar 2. Rangkaian inverter sebagai pembangkit listrik AC.

Untuk meningkatkan efisensi dari wireless power transfer maka dapat meninjau kembali metode transfer daya nirkabel yang digunakan. Salah satu metode yang umum digunakan pada sistem transfer daya nirkabel adalah metode resonant inductive coupling. Metode ini banyak digunakan karena memerlukan rangkaian yang relatif sederhana dan tuning frekuensinya lebih mudah namun tetap memiliki efisiensi yang relatif tinggi [8], [9].

\section{METODE PENELITIAN}

\section{A. Diagram Blok Sistem}

Sistem transfer daya nirkabel merupakan salah satu bagian dari sebuah sistem monitoring kebocoran gas yang melibatkan mobile robot pendeteksi kebocoran gas dan ground station sebagai tempat pengisian daya. Pada ground station terdapat sistem tracking sinar matahari untuk mengoptimalkan panel surya dan sistem transfer daya nirkabel untuk pengisian daya mobile robot itu sendiri. Pada penelitian ini, sistem transfer daya nirkabel merupakan sistem utama yang akan diuji.

Secara umum sistem terbagi menjadi tiga sub-sistem utama yaitu sub-sistem transmitter, receiver, dan pengisian daya. Ketiga sub-sistem ini akan bekerja bersama untuk mentransfer daya secara nirkabel untuk mengisi baterai.

Cara kerja dari keseluruhan sistem secara umum adalah transmitter akan membangkitkan gelombang elektromagnetik pada spectrum VLF yang kemudian akan ditangkap oleh receiver dan diubah kembali menjadi energi listrik. Energi listrik yang sampai pada receiver kemudian akan digunakan untuk mengisi baterai pada mobile robot.

Bagian-bagian pada blok diagram yang ditunjukkan pada gambar 1 terdiri dari 5 komponen. Sumber DC menghasilkan tegangan keluaran antara 10-24 V yang diatur oleh PWM. Duty cycle dari PWM bergantung pada nilai tegangan baterai yang dibaca oleh sensor tengangan. PWM dibangkitkan oleh mikrokontroler untuk mengatur switching dari MOSFET pada inverter dan buck converter. Mikrokontroler yang digunakan untuk membangkitkan PWM adalah Teensy 3.5. Teensy merupakan mikrokontroler berbasis ARM yang dapat diprogram dengan bahasa $\mathrm{C}$ dan juga dapat menggunakan Arduino IDE sebagai compilernya [10]. Kemudian terdapat inverter yang berfungsi untuk mengubah sumber listrik dari DC menjadi AC dengan frekuensi antara $30 \mathrm{kHz}-150 \mathrm{kHz}$. Daya berupa listrik AC ini akan ditransfer secara nirkabel menuju sub-sistem receiver. Skematik dari rangkaian inverter dapat dilihat pada gambar 2. Berikutnya adalah rectifier pada sub- sistem receiver. Daya berupa listrik AC yang ditangkap dari transmitter akan diubah kembali menjadi listrik DC dan digunakan untuk mengisi daya baterai. Untuk mengubah listrik AC menjadi DC digunakan IC rectifier D2SB60 yang dapat menerima arus input maksimum sebesar 2 Ampere. Komponen terakhir berupa charger yang berfungsi mengisi daya lead-acid battery. Charger yang digunakan harus memiliki kontrol yang dapat menyesuaikan output terhadap kondisi baterai.

\section{B. Perancangan Sistem Transfer Daya Nirkabel}

Wireless power transfer atau transfer daya nirkabel menggunakan medan elektromagnetik untuk mentransfer energi antara dua benda. Hal ini biasanya dilakukan dengan menggunakan metode induktif. Energi dikirim melalui kumparan ke perangkat listrik yang kemudian dapat menggunakan energi itu untuk mengisi baterai atau menjalankan perangkat [11].

Tahap-tahap transfer daya secara nirkabel dari secara umum dapat ditinjau pada diagram pada gambar 1 . Pada subsistem transmitter terdapat sumber daya dari sistem dapat berupa listrik dari jala-jala listrik maupun dari sumber DC. listrik dari sumber tersebut kemudian diubah menjadi listrik AC oleh inverter dan diosilasikan pada frekuensi tinggi. Kemudian sinyal akan dikirimkan melalui resonator sumber menuju resonator perangkat. Garis putus-putus menunjukkan bahwa antara sub-sistem transmitter dan receiver tidak terhubung secara fisik menggunakan kabel.

Impedance matching network (IMN) atau rangkaian kompensasi pada sub-sistem transmitter dan receiver seperti yang ditunjukkan pada gambar 3 dan 4 memiliki fungsi mengurangi rugi-rugi daya yang diakibatkan mismatch impedansi antara resonator sumber dengan resonator perangkat. Mismatch impedansi dapat terjadi jika beban pada resonator berubah atau terjadi perpindahan posisi pada kumparan [2].

Salah satu cara untuk meningkatkan efisiensi yang tinggi adalah dengan meninkatkan $Q$ factor dari antena yaitu kumparan transmitter dan receiver. Nilai Q dapat dirumuskan sebagai berikut [12]:

$$
\mathrm{Q}=\frac{L}{R}
$$

Nilai $Q$ berbanding terbalik dengan $R$ yang merupakan resistansi parasitik pada kumparan. Meningkatkan Q sama artinya dengan mengurangi $\mathrm{R}$ sehingga rugi-rugi daya akibat perubahan energy listrik menjadi panas dapat dikurangi. Selain itu nilai Q juga dapat ditingkatkan dengan cara memperbesar induktansi kumparan. Untuk mendapatkan nilai dari induktor yang dibuat secara manual sebagai L2 dapat digunakan rumus sebagai berikut:

$$
\mathrm{L}=\mu_{0} \frac{N^{2} \cdot A}{l}
$$

dimana $\mu_{0}$ adalah permeabilitas inti, $\mathrm{N}$ adalah jumlah lilitan, $\mathrm{A}$ adalah luas penampangsedangkan 1 adalah panjang kawat.

Pada sistem transfer daya nikabel induktansi bocor antara kumparan primer dan kumparan sekundernya sangatlah besar. Hal ini menyebabkan efisiensi transfer daya antara kedua kumparan turun secara drastis. Untuk menghilangkan induktansi bocor maka digunakan metode inductive resonant coupling yang menjadikan kumparan primer dan sekunder 
beresonansi pada frekuensi yang sama dengan menambahkan rangkaian kompensasi.

Pada umumnya rangkaian kompensasi dapat dibuat hanya dengan satu komponen kapasitor saja untuk membentuk rangkaian kompensasi S-S, S-P, P-S, dan P-P. Namun, untuk meningkatkan efisiensi, rangkaian kompensasi yang lebih baik seperti LCL dicetuskan. Rangkaian kompensasi LCL memiliki kelemahan dimana induktor yang digunakan menjadi lebih banyak. Untuk mengurangi banyaknya induktor maka dapat digunakan rangkaian kompensasi LCC yang menggunakan kapasitor sebagai induktor namun tetap memiliki kemampuan yang sama baiknya dengan rangkaian kompensasi LCL [7].

Nilai L pada rangkaian kompensasi S-P dan LCC telah diketahui dari hasil pengukuran. Rangkaian kompensasi S-P ditunjukkan pada gambar 3. Nilai kapasitor yang diperlukan dapat ditentukan dengan menggunakan rumus sebagai berikut [13] :

$$
\omega=\frac{1}{\sqrt{L C}}
$$

Dari persamaan tersebut nilai $\omega$ disubstitusikan menjadi $2 \pi f$, sehingga:

$$
C=\frac{1}{4 \pi^{2} f r^{2} L}
$$

Sedangkan pada rangkaian kompensasi LCC pada gambar 2 nilai masing-masing rangkaian dapat dirumuskan sebagai berikut:

$$
f r=\frac{1}{2 \pi \sqrt{L_{2} C_{2}}}
$$

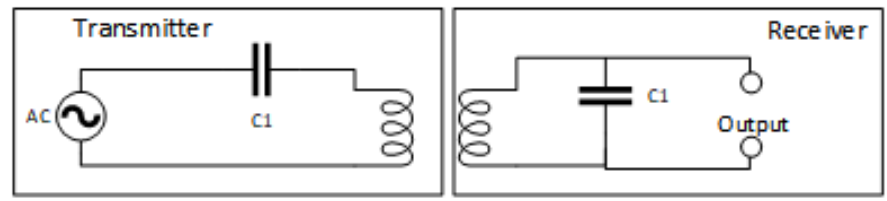

Gambar 3. Rangkaian kompensasi S-P.

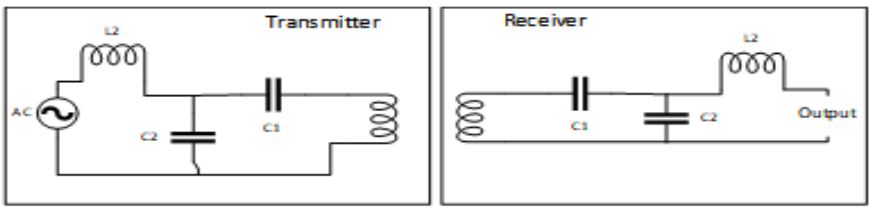

Gambar 4. Rangkaian kompensasi LCC.

Sedangkan nilai kapaitansi C1 pada transmitter dan receiver adalah

$$
\mathrm{C}_{1}=\frac{1}{4 \pi^{2}\left(L_{\text {kumparan }}-L_{2}\right)}
$$

dimana $\mathrm{X}$ adalah reaktansi dengan satuan Ohm, $\mathrm{C}$ merupakan representasi dari kapasitansi dengan satuan Farrad, L adalah induktansi dengan satuan Henry, $f_{\mathrm{r}}$ adalah frekuensi resonansi.

\section{Perancangan Kontrol Pengisian baterai}

Dalam pengisian daya baterai terdapat beberapa jenis kontrol yang biasa digunakan antara lain constant current (CC), constant voltage $(\mathrm{CV})$, constant current-constant voltage(CCCV) [14]. Setiap metode memiliki kelebihan dan kelemahan masing-masing. Pada pengisian daya $\mathrm{CV}$, kontrol yang digunakan lebih mudah dan lebih aman dari metode lain namun pengisiannya lebih lambat dari $\mathrm{CC}$ dan $\mathrm{CC}-\mathrm{CV}$. Pada metode $\mathrm{CC}$, waktu pengisian lebih cepat namun dapat terjadi overcharging jika dibiarkan terlalu lama. Metode CC-CV merupakan gabungan dari dua metode sebelumnya dimana pada saat baterai pada kondisi kosong maka diterapkan CC agar pengisian lebih cepat sedangkan pada saat baterai hampir penuh metode berganti menjadi CV untuk menghindari overcharge.

IC yang digunakan untuk kontrol pengisian daya adalah L200C yang merupakan regulator tegangan dan arus. IC L200C digunakan untuk kontrol CC-CV pada pengisian daya baterai dengan arus maksimum charging pada $700 \mathrm{~mA}$ dan tegangan floating maksimum adalah 7,18 Volt. Skematik dari rangkaian dapat dilihat pada gambar 5 .

\section{Perancangan Kontrol Suplai Daya dengan Buck converter}

Penggunaan converter DC-DC sebagai regulator tegangan memiliki kelebihan dimana DC-DC converter memiliki efisiensi yang lebih tinggi dibandingkan regulator tegangan monolithic seperti IC LM78 Series. Hal ini dikarenakan pada DC-DC converter pengaturan tegangan menggunakan prinsip charge dan discharge pada kapasitor dan inductor. Hal ini berbeda dengan kebanyakan regulator tegangan yang merubah kelebihan tegangan menjadi panas.

Pada penelitian ini, DC-DC converter yang digunakan adalah buck converter. Buck converter sendiri merupakan converter DC-DC yang berfungsi menurunkan tegangan input sehingga tegangan output menjadi lebih kecil.

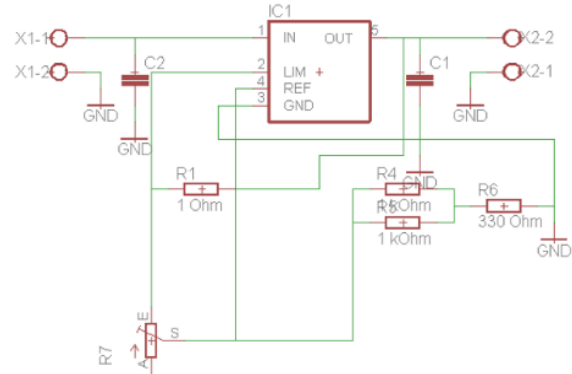

Gambar 5. Rangkaian kontrol pengisi daya dengan IC L200C

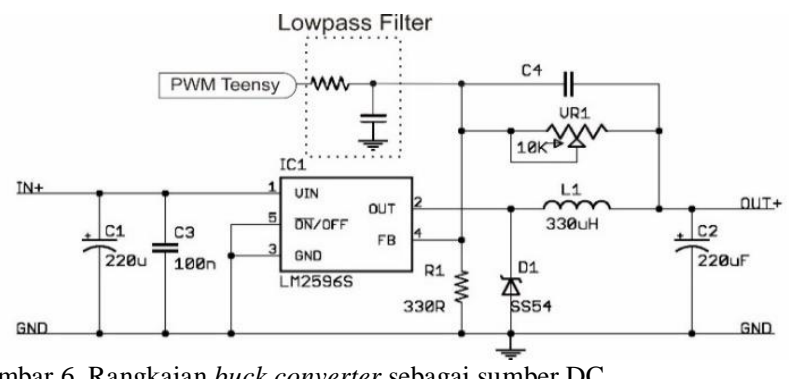

Gambar 6. Rangkaian buck converter sebagai sumber DC.

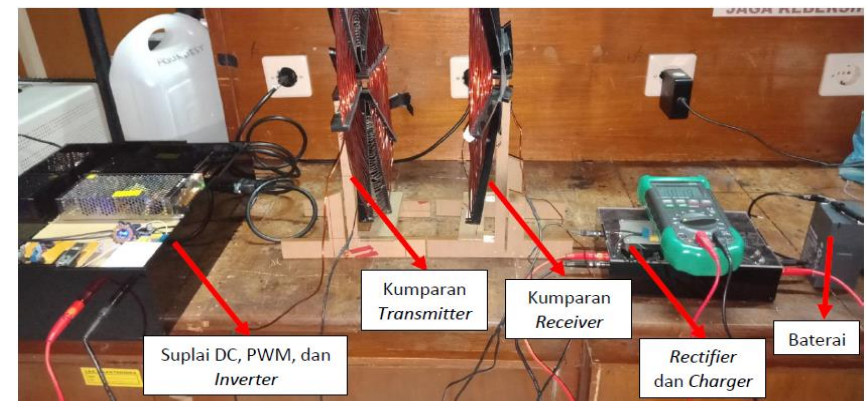

Gambar 1. Hasil realisasi sistem transfer daya nirkabel 
Buck converter yang digunakan adalah IC LM2596 dengan input PWM yang telah dilewatkan low pass filter dengan frekuensi cut-off $1 \mathrm{kHz}$. Tujuan adanya filter adalah agar sinyal PWM menjadi DC murni yang digunakan sebagai sinyal feedback untuk mengatur tegangan regulator tersebut. Skematik rangkaian ini ditunjukkan pada gambar 6 .

\section{HASIL DAN DISKUSI}

\section{A. Sistem Transfer Daya Nirkabel}

Pada bagian perancangan sistem telah dilakukan perancangan inverter dimana nilai frekuensi switching sama dengan frekuensi resonansi yang telah ditentukan dari nilai kapasitansi dan induktansi dari rangkaian kompensasi. Pengujian pertama dari sistem transfer daya nirkabel dilakukan untuk mengetahui besar daya yang dapat dikirimkan secara nirkabel dan efisiensinya dengan menggunakan rangkaian kompensasi S-P dan LCC. Hasil reasisasi sistem transfer daya nirkabel dapat dilihat pada gambar 7.

Pada gambar 1 dan 2 serta sub-bab tinjauan pustaka. telah dijelaskan skematik dari rangkaian kompensasi dan cara mencari nilainya. Dengan diketahui nilai induktansi kumparan transmitter adalah $323 \mathrm{uH}$ dan nilai induktansi kumparan receiver senilai 311,7 maka dapat diketahui nilai-nilai rangkaian lain sebagai berikut sesuai dengan tabel 1 .

Tabel 1.

Nilai komponen pada rangkaian kompensasi

\begin{tabular}{lll}
\hline \hline Rangkaian Kompensasi S- & C transmitter & $7,85 \mathrm{nF}$ \\
\cline { 2 - 3 } $\mathrm{P}$ & C receiver & $8 \mathrm{nF}$ \\
\hline & C1 pada transmitter & $9,19 \mathrm{nF}$ \\
Rangkaian Kompensasi & C1 pada receiver & $9,6 \mathrm{nF}$ \\
LCC & C2 pada transmitter & $53,9 \mathrm{nF}$ \\
& C2 pada receiver & $53,9 \mathrm{nF}$ \\
& L2 pada transmitter & $47 \mathrm{uH}$ \\
& L2 pada receiver & $47 \mathrm{uH}$ \\
\hline \hline
\end{tabular}

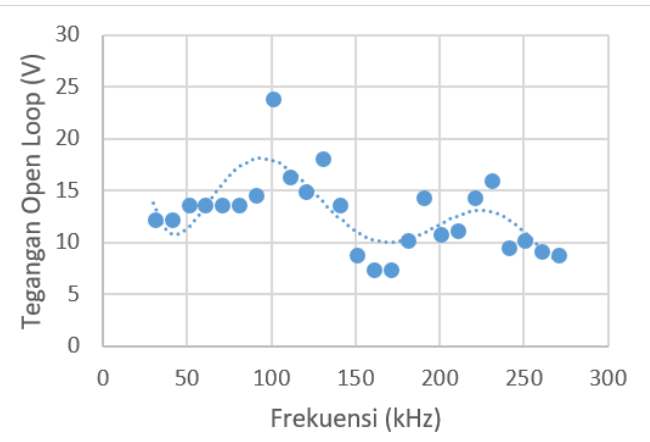

Gambar 2. Keluaran tegangan open loop pada receiver rangkaian kompensasi S-P

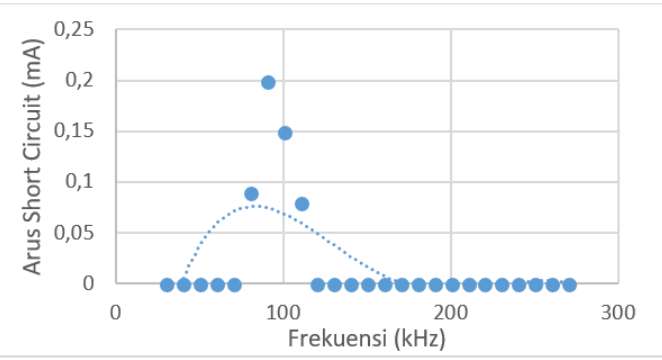

Gambar 3. Keluaran arus short cicuit pada receiver rangkaian kompensasi S-P.

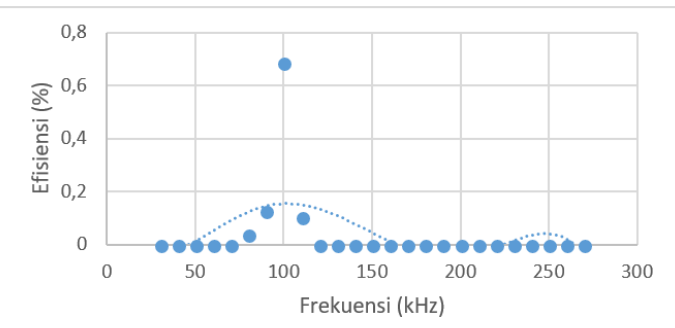

Gambar 4. Efisiensi transfer daya pada rangkaian kompensasi S-P.

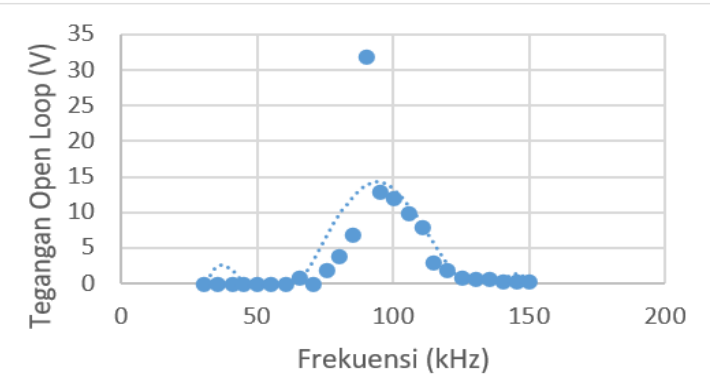

Gambar 5. Keluaran tegangan open loop pada receiver rangkaian kompensasi LCC.

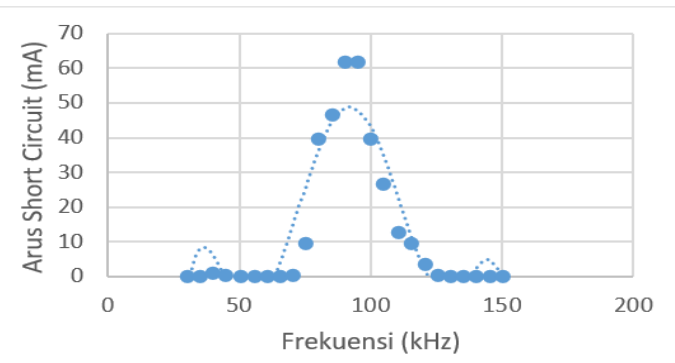

Gambar 6. Keluaran arus short cicuit pada receiver rangkaian kompensasi LCC.

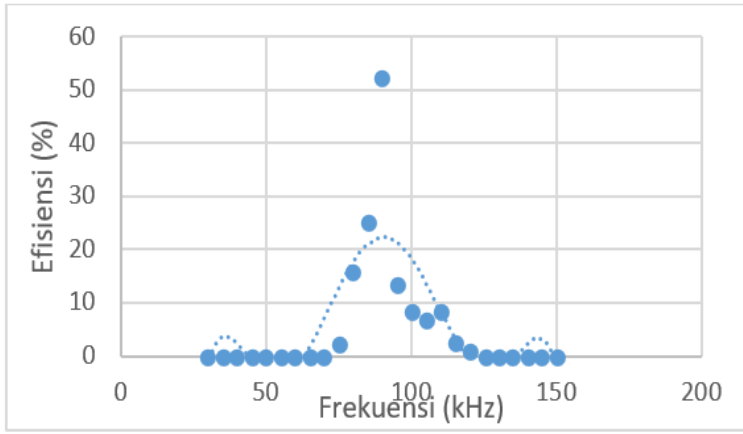

Gambar 7. Efisiensi transfer daya pada rangkaian kompensasi LCC.

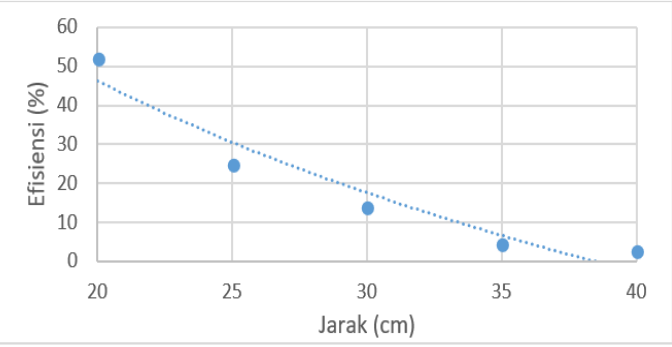

Gambar 8. Grafik efisiensi terhadap jarak antara transmitter dengan receiver 


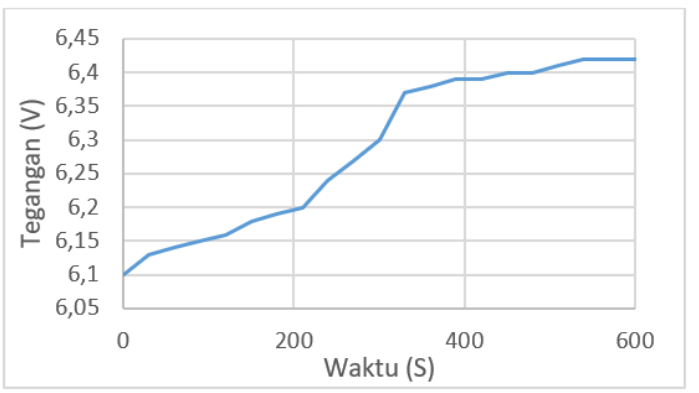

Gambar 9. Grafik tegangan terhadap waktu pada kontrol pengisian daya.

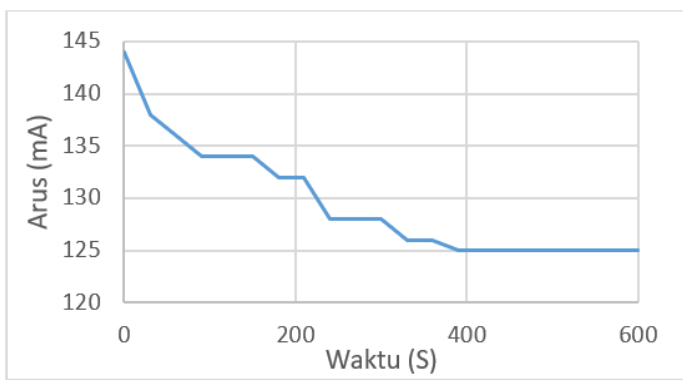

Gambar 10. Grafik arus terhadap waktu pada kontrol pengisian daya.

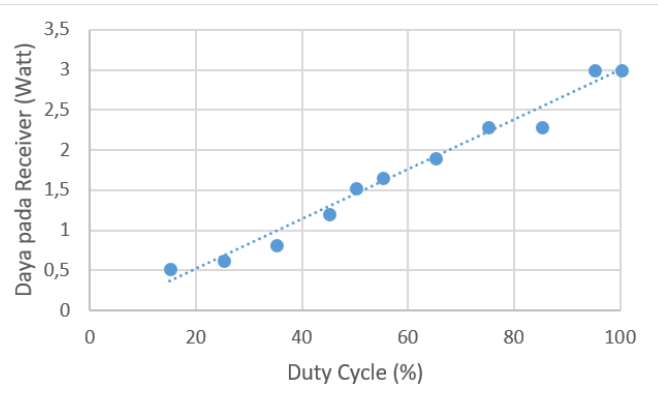

Gambar 11. Grafik daya pada receiver pada saat tegangan pada sumber DC nilainya dikontrol dengan PWM.

Perbandingan grafik pada gambar 8 dan 9 serta gambar 11 dan 12 menunjukkan bahwa persebaran daya pada rangkaian kompensasi S-P terlalu luas jika dibandingkan pada rangkaian kompensasi LCC sehingga efisiensi pada satu titik frekuensi semakin berkurang. Pada gambar 10 dan 13 ditunjukkan perbedaan yang signifikan pada nilai efisiensi daya antara rangkaian kompensasi S-P dengan rangkaian kompensasi LCC. Pada rangkaian kompensasi LCC nilai efisiensi maksimum mencapai 52 persen saat frekuensinya $91 \mathrm{kHz}$ sedangkan pada rangkaian kompensasi $\mathrm{S}-\mathrm{P}$ efisiensi maksimum hanya mencapai 0,7 persen saat frekuensinya $100 \mathrm{kHz}$.

Nilai efisiensi terhadap jarak sistem transfer daya nirkabel yang ditunjukkan pada gambar 14 menunjukkan bahwa nilai efisiensi berkurang secara linear dengan semakin bertambahnya jarak antara transmitter dengan receiver. Pada jarak terdekat yaitu $20 \mathrm{~cm}$ nilai efisiensi dari sistem transfer daya nirkabel mencapai 52 persen.

\section{B. Sistem Pengisian Daya}

Pengujian sistem pengisian daya dilakukan pada saat tegangan baterai sebesar 6 Volt. Pengujian dihentikan saat tegangan output mencapai 7,18 Volt. Grafik pengisian daya baterai dapat dilihat pada gambar 14 dan 15. Pada grafik tersebut dapat diketahui output dari IC L200C terus berubah terhadap waktu. Hal ini dikarenakan kenaikan tegangan pada baterai yang diisi dayanya pada saat tegangan baterai mencapai 7,18 Volt dengan arus yang diisikan pada baterai berada pada minimum untuk menghindari terjadinya overcharge.

\section{Kontrol Suplai Daya}

Gambar 17 menunjukkan bahwa daya yang diterima oleh receiver berbanding lurus dengan duty cycle pada PWM yang mengatur tegangan buck converter. Hal ini menunjukkan bahwa dengan mengontrol duty cycle maka daya yang ditransmisikan juga dapat diatur nilainya. Dari data yang didapatkan pada pengujian diambil nilai efisiensi yang dihitung dengan rumus :

$$
\text { Efisiensi }=\frac{\text { Daya yang diperlukan untuk Charging }}{\text { Daya } \text { pada Receiver }} \times 100
$$

Nilai efisiensi yang didapatkan tiap 30 detik selama 30.990 detik tersebut kemudian akan dirata-rata. Dari data efisiensi ditemukan bahwa nilai efisiensi rata-rata sistem dengan kontrol sumber mencapai $71,5 \%$ sedangkan efisiensi rata-rata sistem tanpa kontrol sumber hanya sebesar $27,9 \%$. Hal ini dapat disimpulkan bahwa adanya kontrol sumber diperlukan untuk menunjang sistem transfer daya nirkabel yang efisien.

\section{KESIMPULAN}

Pada penelitian ini telah dibuat sistem pengisian baterai secara nirkabel. Pada sistem ini, metode resonant inductive coupling dapat mengirimkan daya dengan efisiensi paling tinggi pada frekuensi $91 \mathrm{kHz}$. Dengan rangkaian kompensasi LCC, efisiensi meningkat secara signifikan dibandingkan rangkaian dengan kompensasi S-P. Efisiensi transfer daya paling tinggi dicapai pada jarak $20 \mathrm{~cm}$ dengan nilai mencapai 52 persen. Pengisian daya menggunakan kontrol CC-CV dapat menjaga terjadinya overcharge pada baterai dengan menurunkan arus dan mempertahankan tegangan pada kondisi penuh. Sedangkan kontrol pada sumber daya dapat mengatur daya yang dikirim oleh transmitter dan meningkatkan efisiensi pengisian daya dari $27,9 \%$ menjadi $71,5 \%$.

\section{DAFTAR PUSTAKA}

[1] H. Jiang et al., "A Low-Frequency Versatile Wireless Power Transfer Technology for Biomedical Implants," IEEE Trans. Biomed. Circuits Syst., vol. 7, no. 4, pp. 526-535, Aug. 2013.

[2] V. Yashchenko, V. Turgaliev, D. Kozlov, I. Vendik, and A. Katsay, "Adaptive impedance-matching network for wireless power transfer system with off-center receiver," in 2017 Progress In Electromagnetics Research Symposium - Spring (PIERS), 2017, pp. 2185-2189.

[3] S. Samanta, A. K. Rathore, and D. J. Thrimawithana, "Analysis and Design of Current-Fed Half-Bridge (C)(LC)-( LC) Resonant Topology for Inductive Wireless Power Transfer Application," IEEE Trans. Ind. Appl., vol. 53, no. 4, pp. 3917-3926, Jul. 2017.

[4] X. Mou and H. Sun, "Analysis of multiple segmented transmitters design in dynamic wireless power transfer for electric vehicles charging," Electron. Lett., vol. 53, no. 14, pp. 941-943, 2017.

[5] D. M. Gumelar, M. Rivai, and T. Tasripan, "Rancang Bangun Wireless Electronic Nose Berbasis Teknologi Internet of Things," J. Tek. ITS, vol. 6, no. 2, Oct. 2017.

[6] H. Avrilyantama, M. Rivai, D. Purwanto, and J. A. R. Hakim, "Pengembangan Robot Hexapod untuk Melacak Sumber Gas," J. Tek. ITS, vol. 4, no. 1, p. 7, 2015. 
[7] S. Li, W. Li, J. Deng, T. D. Nguyen, and C. C. Mi, “A Double-Sided LCC Compensation Network and Its Tuning Method for Wireless Power Transfer," IEEE Trans. Veh. Technol., vol. 64, no. 6, pp. 2261-2273, Jun. 2015.

[8] I. R. H. Yaldi, S. K. A. Rahim, and M. R. Ramli, "Compact rectifier design for RF energy harvesting," in Applied Electromagnetics (APACE), 2016 IEEE Asia-Pacific Conference on, 2016, pp. 258-262.

[9] Y. Do Chung and J. Kim, "Conceptual design and characteristics of wireless power charging system for HTS magnet using copper resonance coupling coils," in Electromagnetic Compatibility (APEMC), 2017 AsiaPacific International Symposium on, 2017, pp. 141-143.

[10] L. Riadhi, M. Rivai, and F. Budiman, "Sistem Pengaturan Oksigen Terlarut Menggunakan Metode Logika Fuzzy Berbasis Mikrokontroler Teensy Board," J. Tek. ITS, vol. 6, no. 2, Sep. 2017.
[11] A. Bomber and L. Rosa, "Wireless Power Transmission: An Obscure History, Possibly a Bright Future," Phys. 464 Appl. Opt., pp. 1-15, 2006.

[12] R. Murakami, M. Inamori, and M. Morimoto, "Effects of Q factor on wireless power transmission by magnetic resonant coupling," 2016, pp. 139-143.

[13] D. I. Pratiwi, M. Rivai, and F. Budiman, "Rancang Bangun Deteksi Jalur Pipa Terpendam Menggunakan Mobile Robot dengan Metal Detector," $J$. Tek. ITS, vol. 6, no. 1, pp. 168-173, 2017.

[14] C. S. Lee, H. C. Lin, and S.-Y. Lai, "Development of Fast Large LeadAcid Battery Charging System Using Multi-state Strategy," vol. 2, p. 10, 2013. 